\title{
Deep Eutectic Solvent-Based Microwave-Assisted Extraction of Baicalin from Scutellaria baicalensis Georgi
}

\author{
Hui Wang, ${ }^{1,2}$ Xiaodi Ma, ${ }^{1}$ Qibin Cheng, ${ }^{1}$ Xiaoli Xi, ${ }^{1}$ and Liwei Zhang ${ }^{1}$ \\ ${ }^{1}$ Institute of Molecule Science, Key Laboratory of Chemical Biology and Molecular Engineering of Ministry of Education, \\ Shanxi University, Taiyuan 030006, China \\ ${ }^{2}$ Taiyuan University of Science and Technology, Taiyuan, Shanxi 030024, China
}

Correspondence should be addressed to Liwei Zhang; lwzhang@sxu.edu.cn

Received 9 October 2017; Revised 6 December 2017; Accepted 11 December 2017; Published 8 January 2018

Academic Editor: Dimitris P. Makris

Copyright (C) 2018 Hui Wang et al. This is an open access article distributed under the Creative Commons Attribution License, which permits unrestricted use, distribution, and reproduction in any medium, provided the original work is properly cited.

\begin{abstract}
Deep eutectic solvents (DESs) have attracted significant attention as green media for the extraction and separation of natural compounds from Chinese medicine. In this study, a hydrophobic DESs-based microwave-assisted extraction (MAE) was successfully used to efficiently extract baicalin from Scutellaria baicalensis Georgi. Firstly, DecA: $\mathrm{N}_{4444}-\mathrm{Cl}$ (DES-1, molar ratio $1: 2$ ) was screened and selected as the most appropriate DES by comparing the extraction yield in different hydrophobic DESs. Based on the extraction yield of baicalin, response surface methodology (RSM) was employed to model and optimize the parameters (extraction temperature, liquid-solid ratio, and extraction time). Furthermore, the maximum yield of $106.96 \mathrm{mg} \cdot \mathrm{g}^{-1}$ was achieved under optimum conditions in DES-containing aqueous solutions (33 vol\% water content), which reached a similar level that was conducted using the pharmacopoeia procedure $\left(104.94 \mathrm{mg} \cdot \mathrm{g}^{-1}\right)$. These results indicated that the proposed method is an excellent alternative for the extraction of baicalin.
\end{abstract}

\section{Introduction}

The biological activity of Scutellaria baicalensis Georgi, a traditional Chinese herbal medicine, is well known for antiinflammation, anticancer, treating bacterial and viral infections of the respiratory system, detoxifying toxicosis, reducing total cholesterol level, and decreasing blood pressure [1-3]. The main active ingredient of Scutellaria baicalensis Georgi is baicalin, which has been demonstrated to decrease blood pressure, have antitoxin and antifever effect, and reduce the risk of cardiovascular diseases [4-7]. Therefore, baicalin is widely used in medicine, health foods, functional products, and cosmetics. Currently, baicalin is mainly extracted from Scutellaria baicalensis Georgi using traditional methods, such as hot reflux-assisted extraction (HRAE) and ultrasoundassisted extraction (UAE) [8-11]. However, these traditional methods have many disadvantages, such as the consumption of large volumes of solvent and energy, low yields, lengthy extraction procedures, and serious environmental pollution. Thus, it is highly desirable to identify an efficient and green extraction method for baicalin.
Deep eutectic solvents (DESs) are commonly made up of two or more compounds, a combination of hydrogen bond donors (HBDs) and hydrogen bond acceptors (HBAs), which form liquids upon mixing with melting points below that of the individual components due to self-association [12, 13]. DESs show great promise as green solvents due to their biodegradability, low toxicity [14], easy preparation [15], and novel properties [16]. DESs are regarded as designer solvents with the appropriate selection of individual components in terms of molecular structure, chemical nature, ratio, and water content $[17,18]$. Based on these unique characteristics, there are reports on the use of hydrophilic DESs as extraction media to extract bioactive compounds from plants [19-21]. Recently, Li [22] reported that ChCl-based DESs (choline chloride : lactic acid) can be used for the extraction of baicalin from Radix Scutellariae, but the process has a low extraction yield. Considering the physicochemical properties of baicalin and the designable natural of DESs, in this study, we attempted to prepare a hydrophobic DES for highly efficient extraction of baicalin. 
In order to enhance the extraction yield of baicalin, nine different hydrophobic DESs which consisted of decanoic acid and different quaternary ammonium salts in different molar ratios were successfully prepared in this study. Then, the most suitable DES with the highest extraction yield was determined by evaluating the extraction process in different hydrophobic DESs. To maximize the extraction yield of baicalin, independent variables including extraction temperature, liquid-solid ratio, and extraction time were optimized using the Box-Behnken design. Under the optimal conditions, we further verified the feasibility and superiority of the hydrophobic DESs-based MAE through comparing with conventional methods (e.g., HRAE, UAE). Lastly, the microstructure alterations in the samples before and after extraction were observed using scanning electron microscope (SEM) in order to determine the extraction mechanism.

\section{Materials and Methods}

2.1. Materials and Reagents. Dried Scutellaria baicalensis Georgi was purchased from the Scutellaria baicalensis Georgi Planting Base in Lingchuan county (Shanxi, China). It was milled, screened using 60 mesh stainless steel sieves, and then stored in closed desiccators for use. Baicalin (>93.3\%), standard substance, was purchased from National Institutes for Food and Drug Control.

Decanoic acid (DecA, purity $>98.0 \%$ ), tetrabutylammonium chloride $\left(\mathrm{N}_{4444}-\mathrm{Cl}\right.$, purity $\left.>98.0 \%\right)$, tetraoctylammonium bromide $\left(\mathrm{N}_{8888}-\mathrm{Br}\right.$, purity $\left.>98.0 \%\right)$, methyltrioctylammonium chloride $\left(\mathrm{N}_{8881}-\mathrm{Cl}\right.$, purity $\left.>98.0 \%\right)$, and methyltrioctylammonium bromide $\left(\mathrm{N}_{8881}-\mathrm{Br}\right.$, purity $\left.>98.0 \%\right)$ were purchased from Xiya Chemistry Co., Ltd. (Shandong, China). Methanol, ethanol, phosphoric acid, and other organic solvents of HPLC grade were from MREDA (MREDA Technology Inc., Beijing, China). Water was deionized.

2.2. HPLC Analysis. HPLC analysis was performed using an Elite HPLC system (Agilent, Germany) equipped with a high-pressure gradient (G1311C), a VWD detector (G1314B), an autosampler (G1329B), and a column oven (GT-30). Data processing was carried out using Agilent Open LAB CDS Chemstation edition Software Ver. C. 01.07 (Agilent Technologies, Waldbronn, Germany). HPLC analysis was conducted on a Venusil XBP-C18 $(4.6 \mathrm{~mm} \times 250 \mathrm{~mm}, 5 \mu \mathrm{m}$, $100 \AA$ ). The mobile phase was $\mathrm{CH}_{3} \mathrm{OH}(\mathrm{A})$ and $0.4 \%$ phosphoric acid (B) at a flow rate of $1 \mathrm{~mL} \cdot \mathrm{min}^{-1}$. The column temperature was controlled at $40^{\circ} \mathrm{C}$. Detection was performed at a wavelength of $278 \mathrm{~nm}$.

2.3. Preparation of Hydrophobic DESs. Decanoic acid (DecA) was mixed with quaternary ammonium salts $\left(\mathrm{N}_{4444}-\mathrm{Cl}\right.$, $\mathrm{N}_{8881}-\mathrm{Cl}, \mathrm{N}_{8881}-\mathrm{Br}$, and $\mathrm{N}_{8888}-\mathrm{Br}$ ) at molar ratio of $2: 1,1: 1$, and $1: 2$, respectively, in a sealed glass bottle. The mixture was then heated in a water bath at $35^{\circ} \mathrm{C}$ until it was a transparent liquid and then cooled to room temperature for $12 \mathrm{~h}$. The hydrophobic DESs were further dried in a desiccator in the presence of $\mathrm{P}_{2} \mathrm{O}_{5}$. The prepared DESs are listed in Table 1 . The water content in the DESs was $7,13,20,27$, and
TABLE 1: Different composition of DESs applied in this work.

\begin{tabular}{lccc}
\hline Abbreviation & HBD & Type of HBA & HBD/HBA ratio \\
\hline DES-1 & & & $1: 2$ \\
DES-2 & DecA & $\mathrm{N}_{4444}-\mathrm{Cl}$ & $1: 1$ \\
DES-3 & & & $2: 1$ \\
DES-4 & & & $1: 2$ \\
DES-5 & DecA & $\mathrm{N}_{8881}-\mathrm{Cl}$ & $1: 1$ \\
DES-6 & & & $2: 1$ \\
DES-7 & DecA & $\mathrm{N}_{8881}-\mathrm{Br}$ & $2: 1$ \\
DES-8 & & $\mathrm{N}_{8888}-\mathrm{Br}$ & $1: 1$ \\
DES-9 & DecA & & $2: 1$
\end{tabular}

33 vol\%, respectively. All the DESs solutions were equally homogeneous.

2.4. Solubility Tests. Solubility tests were carried out using distilled water, $70 \%$ ethanol, and DESs with an excess of the tested compound in a capped bottle and stirring at $40^{\circ} \mathrm{C}$ for $2 \mathrm{~h}$. The resulting liquids containing undissolved solid compounds were centrifuged and the supernatant was transferred to a $5 \mathrm{~mL}$-microtube, diluted with methanol, and vortexed to a homogeneous solution. The concentration of baicalin in the solution was monitored by HPLC. All solubility tests were performed in triplicate.

2.5. Extraction of Baicalin. Scutellaria baicalensis Georgi was pulverized to finer than 60 mesh; a $0.5 \mathrm{~g}$ sample was dispersed in $8 \mathrm{~mL}$ DESs in a two-neck pear shaped flask and then extracted in the microwave reactor under the following optimized conditions: ratio of solvent to raw material $\left(16 \mathrm{~mL} \cdot \mathrm{g}^{-1}\right)$, extraction time $(5 \mathrm{~min})$, extraction temperatures $\left(60^{\circ} \mathrm{C}\right)$, and extraction power $(900 \mathrm{~W})$. The resulting solution was filtered through a $0.45-\mu \mathrm{m}$ syringe filter before being used. All experiments were performed in triplicate.

2.6. Comparison Experiments. In order to evaluate the efficiency of the DES-based microwave-assisted extraction method, different extraction procedures were compared. Three common extraction techniques were selected as follows: $\operatorname{MAE}\left(85^{\circ} \mathrm{C}, 23 \mathrm{~mL} \cdot \mathrm{g}^{-1}, 900 \mathrm{~W}\right.$ for $\left.10 \mathrm{~min}\right)$, UAE $\left(23 \mathrm{~mL} \cdot \mathrm{g}^{-1}, 900 \mathrm{~W}\right.$ for $\left.10 \mathrm{~min}\right)$, and $\operatorname{HRAE}\left(80^{\circ} \mathrm{C}, 133 \mathrm{~mL} \cdot \mathrm{g}^{-1}\right.$, for $3 \mathrm{~h}$, in the Chinese pharmacopoeia).

\section{Results and Discussion}

3.1. Comparison of Solubility. Dissolution of the active ingredients in herbal medicines is essential for the extraction process, which can be compared directly and evaluated accurately by equilibrium solubility. Therefore, the equilibrium solubility of baicalin in different solvents (e.g., water, 70\% ethanol, and DESs) at room temperature was determined for screening and comparison, respectively, and the results are shown in Table 2. As shown in Table 2, the equilibrium solubility of baicalin in DES-1, DES-2, and DES-3 was greater than those in water and ethanol. The solubility of baicalin 
TABLE 2: Solubility of baicalin in different solvents.

\begin{tabular}{lcc}
\hline Number & Solvents & Solubility of baicalin $\left(\mathrm{mg} \cdot \mathrm{mL}^{-1}\right)$ \\
\hline$(1)$ & Water & 0.08 \\
$(2)$ & $70 \%$ Ethanol & 1.85 \\
$(3)$ & DES-1 & 19.73 \\
$(4)$ & DES-2 & 2.74 \\
$(5)$ & DES-3 & 2.23 \\
$(6)$ & DES-4 & 1.77 \\
$(7)$ & DES-5 & - \\
$(8)$ & DES-6 & 1.17 \\
$(9)$ & DES-7 & 1.3 \\
$(10)$ & DES-8 & - \\
$(11)$ & DES-9 & 1.28 \\
\hline
\end{tabular}

in DES-1 peaked at $19.73 \mathrm{mg} \cdot \mathrm{mL}^{-1}$, which was approximately 240 times the solubility of baicalin in water and 10 times the solubility of baicalin in $70 \%$ ethanol, respectively. We speculate that DecA can form strong intermolecular hydrogen bonding with $\mathrm{N}_{4444}-\mathrm{Cl}$, while baicalin is a hydroxy compound. Therefore, similar polarity between molecules of DES-1 and baicalin is responsible for their high dissolution [23].

From Table 2, it can be seen that there is large variation in the equilibrium solubility of baicalin in different DESs. These results indicated that not only solvent polarity but also other factors such as intermolecular interaction, and especially the ability to form hydrogen bonds between the solvents and baicalin as well as the physical properties of the solvents (e.g., viscosity and surface tension), could affect the solubility of the solute.

3.2. Comparison of the Extractability of DESs. The extraction efficiency of nine different hydrophobic DESs was investigated using MAE under the same conditions: extraction time $(5 \mathrm{~min})$, extraction temperature $\left(60^{\circ} \mathrm{C}\right)$, power $(500 \mathrm{~W})$, and liquid-solid ratio $\left(16 \mathrm{~mL} \cdot \mathrm{g}^{-1}\right)$. As shown in Figure 1, the results indicated that DES-1 exhibited the strongest extraction efficiency, and the extraction yield reached $50 \mathrm{mg} \cdot \mathrm{g}^{-1}$. Thus, DES-1 was screened for further experiments.

From Figure 1, it can be seen that the extraction yield of baicalin in nine DESs has significant difference. In this study, DecA was designated as the HBD, and the HBAs were chosen from quaternary ammonium salts with different carbon chain lengths. These results indicated that the HBA type and the HBD/HBA molar ratio showed a clear effect on the extraction yield of baicalin. It is generally believed that the extraction efficiency of target compounds can be affected by polarity, diffusion, solubility, viscosity, and surface tension [23].

Comparison among DESs formed with HBD-HBA $\left(\mathrm{N}_{4444}-\mathrm{Cl}, \mathrm{N}_{8881}-\mathrm{Cl}, \mathrm{N}_{8881}-\mathrm{Br}\right.$, and $\left.\mathrm{N}_{8888}-\mathrm{Br}\right)$ indicated that extraction yield decreased a little along with the increase of the length of alkyl chain. This is the reason that the alkyl chain length was longer, the polarity was lower, and the viscosity was higher, so the solubility of baicalin decreased [24].

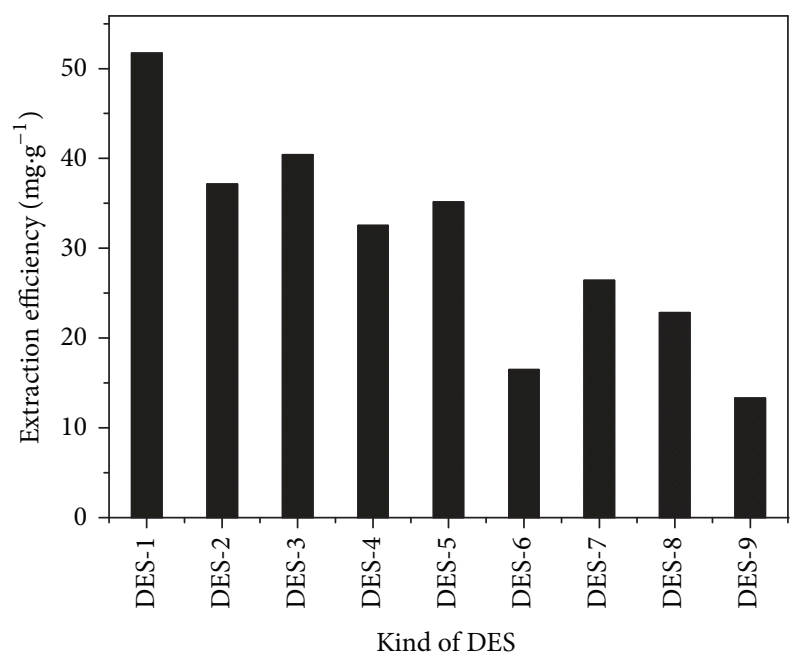

FIGURE 1: Extracted amounts of baicalin using different types of DESs.

TABLE 3: Variables in Box-Behnken design.

\begin{tabular}{lccc}
\hline Factor & \multicolumn{3}{c}{ Actual and coded levels used for the } \\
& Low $(-1)$ & $\begin{array}{c}\text { Medium }(0) \\
\text { conditions }\end{array}$ & High $(+1)$ \\
\hline A: temperature $\left({ }^{\circ} \mathrm{C}\right)$ & 70 & 80 & 90 \\
$B:$ time (min) & 5 & 10 & 15 \\
$C:$ liquid-solid ratio & 10 & 20 & 30 \\
Dependent variable & \multicolumn{3}{c}{ Constrains } \\
$R 1=$ baicalin $/(\mathrm{g} / \mathrm{mg})$ & \multicolumn{3}{c}{ Maximize } \\
\hline
\end{tabular}

Comparison among DES-1, DES-2, and DES-3 indicated that the extraction yield with DES-1 was maximal. When the HBD/HBA molar ratio decreased from $2: 1$ to $1: 2$, the amounts of HBA increased, and thus resulted in the decrease in viscosity and surface tension, which would enhance their extraction efficiency $[25,26]$.

3.3. Optimization of the Extraction Conditions by RSM. According to the above results, DES-1 was selected as the most appropriate DES for the optimization process to maximize the extraction yield of baicalin. In order to define the effect of various independent variables on extraction yield, single-factor experiments were carried out to select the main variables for the Box-Behnken design (BBD). On the basis of the above single-factor tests, three independent variables including extraction temperature $(A)$, extraction time $(B)$, and the liquid-solid ratio $(C)$ were selected and each factor in the experiment was established and coded at three levels by associated minus signs $(-1)$ for low levels, zero (0) representing the center value, and plus signs $(+1)$ for high levels. The experimental design matrix and levels are shown in Table 3. Then, 3 factors and 3 levels were selected for use in the BBD and 17 experimental runs were employed in this study. The extraction yield of baicalin was set as the response to maximize the value. 
TABLE 4: Box-Behnken design with independent variables and measured response.

\begin{tabular}{|c|c|c|c|c|}
\hline Run & $\begin{array}{c}\text { Factor } A: \\
\text { temperature } /{ }^{\circ} \mathrm{C}\end{array}$ & $\begin{array}{l}\text { Factor } B \text { : } \\
\text { time } / \mathrm{min}\end{array}$ & $\begin{array}{c}\text { Factor } C: \\
\text { liquid-solid } \\
\text { ratio } /\left(\mathrm{mL} \cdot \mathrm{g}^{-1}\right)\end{array}$ & Baicalin $/\left(\mathrm{mg} \cdot \mathrm{g}^{-1}\right)$ \\
\hline (1) & 90 & 10 & 30 & 82.82 \\
\hline (2) & 70 & 10 & 10 & 73.63 \\
\hline (3) & 70 & 5 & 20 & 76.23 \\
\hline (4) & 80 & 5 & 30 & 79.01 \\
\hline (5) & 90 & 5 & 20 & 73.89 \\
\hline (6) & 90 & 15 & 20 & 79.89 \\
\hline (7) & 80 & 15 & 10 & 73.48 \\
\hline (8) & 80 & 15 & 30 & 74.71 \\
\hline (9) & 80 & 10 & 20 & 86.38 \\
\hline (10) & 90 & 10 & 10 & 78.35 \\
\hline (11) & 70 & 15 & 20 & 66.59 \\
\hline (12) & 80 & 10 & 20 & 86.68 \\
\hline (13) & 70 & 10 & 30 & 77.95 \\
\hline (14) & 80 & 10 & 20 & 86.29 \\
\hline (15) & 80 & 10 & 20 & 85.89 \\
\hline (16) & 80 & 10 & 20 & 87.02 \\
\hline (17) & 80 & 5 & 10 & 69.43 \\
\hline
\end{tabular}

The BBD experiment yielded 17 different formulations expressed in natural units, and the responses are summarized in Table 4. The nonlinear regression fitting based on the quadratic model of the Design-Expert software (trial version 8.0.6.1, Stat-Ease Inc., Minneapolis, MN, USA) was employed to express baicalin extraction yield $\left(Y_{\text {Baicalin }}\right)$ in the equation of dependent variables shown below:

$$
\begin{aligned}
Y_{\text {Baicalin }}= & -197.10+6.08 A+1.01 B+2.28 C \\
& +0.078 A B+3.7510^{-3} A C-0.042 B C \\
& -0.041 A^{2}-0.33 B^{2}-0.041 C^{2} .
\end{aligned}
$$

Table 5 shows the analysis of variance (ANOVA) for the quadratic model. High coefficient determination $\left(r^{2}=\right.$ $0.9955)$ and nonsignificant lack of fit ( $p$ value of 0.1058 ) indicated that the models were accurate and satisfactory. As shown in Table 5, the interaction terms $A B$ and $B C$ were significant $(p<0.01$ and $p<0.05)$, indicating a significant effect on baicalin yield. The "Pred $R$-Squared" of 0.9447 is in reasonable agreement with the "Adj $R$-Squared" of 0.9898 .

The three-dimension surface plots indicated that superposed effects were employed to investigate the interactions between the different variables of extraction temperature $(A)$, extraction time $(B)$, and the liquid-solid ratio $(C)$ on the extraction yield of baicalin (Figures 2(a)-2(c)). In general, the relationship between the extraction yield and the single variable can be described by a quadratic parabola, and the results indicated that the extraction yield gradually enhanced with increasing temperature, extraction time, and the liquidsolid ratio and then decreased to an extent.

Overall, the temperature and extraction time were more important than the liquid-solid ratio. Figure 2(a) shows that the liquid-solid ratio had little effect on extraction efficiency when the extraction time was fixed. As shown in Figure 2(b), when the liquid-solid ratio was fixed, the extraction yield gradually rose with increasing temperature, reached a maximum at $84^{\circ} \mathrm{C}$, and then decreased. Therefore, the optimal temperature was considered to be $84^{\circ} \mathrm{C}$. This increase in extraction yield can be explained by an acceleration of mass transfer caused by increased temperature. However, an excessively high temperature can cause activity loss, damage the target compounds, and increase the solubility of impurities, resulting in a decrease in the extraction yield. As shown in Figure 2(c), when the temperature was fixed, the extraction yield of baicalin increased with increasing extraction time from 5 to $11 \mathrm{~min}$. The yield peaked after $11 \mathrm{~min}$ and then significantly decreased. Therefore, the optimal extraction time was determined to be $11 \mathrm{~min}$. Prolonging the irradiation time led to full extraction of the target compounds from the solvent and increasing the extraction time up to $11 \mathrm{~min}$ resulted in little volatilization and decomposition, resulting in a small decrease in the extraction yield.

The extraction conditions were optimized using the model equation by solving a regression equation with the estimated extraction yield of baicalin. According to optimization of the regression model, the optimum conditions were as follows: extraction temperature of $85^{\circ} \mathrm{C}$, extraction 
TABLE 5: The ANOVA for the experimental results of the BBD.

\begin{tabular}{|c|c|c|c|c|c|c|}
\hline Source & $\begin{array}{l}\text { Sum of } \\
\text { squares }\end{array}$ & $\mathrm{df}$ & $\begin{array}{c}\text { Mean } \\
\text { square }\end{array}$ & $\begin{array}{c}F \\
\text { value }\end{array}$ & $\begin{array}{c}p \text { value } \\
\text { Prob }>F\end{array}$ & \\
\hline Model & 648.15 & 9 & 72.02 & 173.65 & $<0.0001$ & Significant \\
\hline A: temperature & 52.79 & 1 & 52.79 & 127.28 & $<0.0001$ & \\
\hline$B$ : time & 1.89 & 1 & 1.89 & 4.56 & 0.0701 & \\
\hline $\begin{array}{l}C \text { : liquid-solid } \\
\text { ratio }\end{array}$ & 48.02 & 1 & 48.02 & 115.79 & $<0.0001$ & \\
\hline$A B$ & 61.15 & 1 & 61.15 & 147.45 & $<0.0001$ & \\
\hline$A C$ & 0.00562 & 1 & 0.0052 & 0.014 & 0.9106 & \\
\hline$B C$ & 17.43 & 1 & 17.43 & 42.03 & 0.0003 & \\
\hline$A^{2}$ & 72.03 & 1 & 72.03 & 173.68 & $<0.0001$ & \\
\hline$B^{2}$ & 280.77 & 1 & 280.77 & 677.01 & $<0.0001$ & \\
\hline$C^{2}$ & 71.77 & 1 & 71.77 & 173.05 & $<0.0001$ & \\
\hline Residual & 2.90 & 7 & 0.41 & & & \\
\hline Lack of fit & 2.18 & 3 & 0.73 & 4.03 & 0.1058 & $\begin{array}{c}\text { Not } \\
\text { significant }\end{array}$ \\
\hline Pure error & 0.72 & 4 & 0.18 & & & \\
\hline Cor total & 651.05 & 16 & & & & \\
\hline$R 2$ & & & 0.9955 & & & \\
\hline Adj $R 2$ & & & 0.9898 & & & \\
\hline Pred $R 2$ & & & 0.9447 & & & \\
\hline
\end{tabular}

time of $10 \mathrm{~min}$ and liquid-solid ratio of $23.11 \mathrm{~mL} \cdot \mathrm{g}^{-1}$, and the maximum extraction yield was $87.02 \mathrm{mg} \cdot \mathrm{g}^{-1}$.

The fixed optimum conditions were used for the verification test, and the prediction was determined from the regression model. Based on the operability of the process, the independent variables were modified to $85^{\circ} \mathrm{C}, 10 \mathrm{~min}$, and $23 \mathrm{~mL} \cdot \mathrm{g}^{-1}$, respectively. Under the fixed optimum conditions, parallel tests were repeated three times, and the actual extraction yield obtained was $86.99 \mathrm{mg} \cdot \mathrm{g}^{-1}$, which was in accordance with the predicted value. These results confirmed that the response model was suitable for optimization.

3.4. Effect of Water Content in the DESs. As mentioned above, the quaternary ammonium salt-based DESs have strong design ability when the composition and molar ratio between HBD and HBA are adjusted. In addition, the properties of DESs can be tailored in a controlled way by adding water to facilitate their application. It was reported that the addition of water to DESs can change the viscosity, surface tension, and polarity, which may affect the extraction efficiency of target compounds [27].

In order to achieve a better extraction yield, the water content of the hydrophobic DESs-containing aqueous solutions on extraction yield was investigated. Due to the weak intersolubility of DES-1 and water, the water content was set at $0,7,13,20,27$, and 33 vol\% in the DES-water solutions. The DESs-containing aqueous solutions at different concentrations were used to extract baicalin under the above optimum conditions, and the results are shown in Figure 3. The results indicated that the extraction yield increased constantly with water content, and reached $106.96 \mathrm{mg} \cdot \mathrm{g}^{-1}$ at a water content of $33 \mathrm{vol} \%$ in the DES-1 containing aqueous solutions.

We speculate that reasons for this phenomenon may be due to the addition of water, which may lead to a significant alteration in the physical and chemical characteristics as well as the hydrogen bonding network of DESs. The above predictions were confirmed by our results, which indicated that changing polarity of the diluted DESs has an obvious influence on the extraction capacity of different types of DESs. Furthermore, for hydrophobic DESs, the optimal water content may be also correlated with the viscosity of DESs.

3.5. Comparison of Extraction Methods. Comparisons of different methods and extraction solvents were carried out, and the extraction yield of baicalin in $33 \mathrm{vol} \%$ DESs-containing aqueous solutions and $70 \mathrm{vol} \%$ ethanol under the MAE, UAE, and HRAE was determined, respectively. The extraction yields using these methods are listed in Table 6.

The results showed that the extraction efficiency obtained with these methods was in accordance with the following order: MAE > HRAE > UAE. As shown in Table 6, the maximum extraction yield was $106.96 \mathrm{mg}^{-\mathrm{g}^{-1}}$ using the DESbased MAE, which is slightly higher than that extracted by

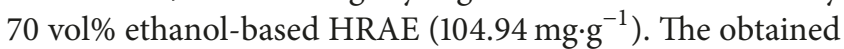
extraction yields by these two methods were very similar; however, the extraction time in DES-based MAE was only 
Design-Expert software Factor coding: actual baicalin

- Design points above predicted value

- Design points below predicted value

87.02

66.59

$X 1=B$ : time

$X 2=C:$ liquid to solid

Actual factor

A: temperature $=80.00$

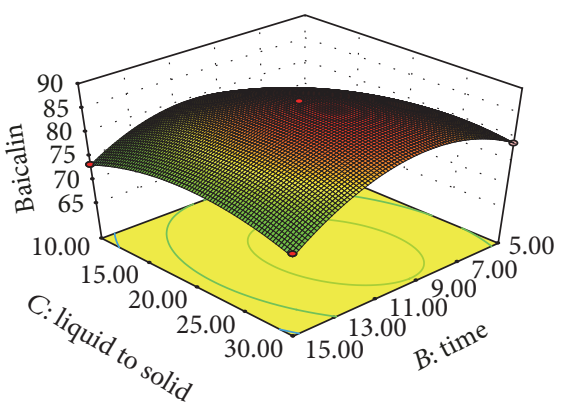

(a)

Design-Expert software

Factor coding: actual

baicalin

- Design points above predicted value

- Design points below predicted value

87.02

66.59

$X 1=A$ : temperature

$X 2=B$ : time

Actual factor

C: liquid to solid $=20.00$
Design-Expert software

Factor coding: actual

baicalin

- Design points above predicted value

- Design points below predicted value

87.02

66.59

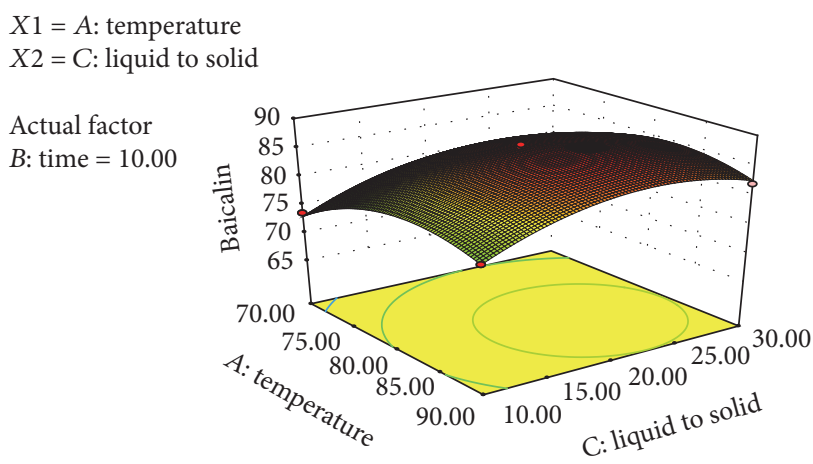

(b)

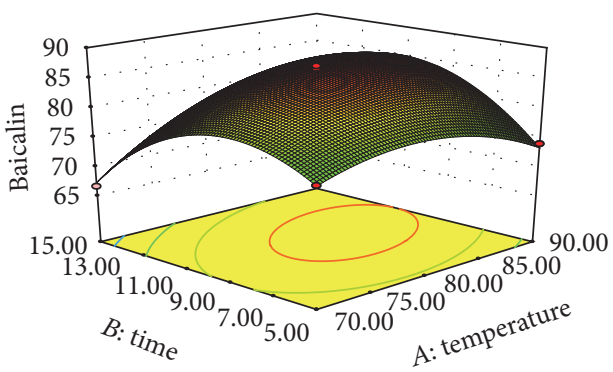

(c)

FiguRE 2: 3D response surface plots of baicalin.

TABLE 6: Extraction contents of the baicalin using various extraction procedures.

\begin{tabular}{lcc}
\hline Extract method & Solvent & Baicalin $\left({\left.\mathrm{mg} \cdot \mathrm{g}^{-1}\right)}^{\text {UAE }}\right.$ \\
\multirow{2}{*}{ HRAE } & $70 \%$ ethyl alcohol & 60.92 \\
& Moisture content 33\% of DES & 69.05 \\
\multirow{2}{*}{ MAE } & $70 \%$ ethyl alcohol & 104.94 \\
& Moisture content 33\% of DES & 93.71 \\
& $70 \%$ ethyl alcohol & 95.14 \\
\hline
\end{tabular}

$10 \mathrm{~min}$, which was far less than that with $70 \%$ ethanol-based $\operatorname{HRAE}(3 \mathrm{~h})$.

These results showed that ethanol-based HRAE $(3 \mathrm{~h})$ and DESs treatment made a significant contribution to the extraction efficiency of baicalin. When microwave radiation heating was compared with traditional heating and ultrasonic penetration, it was found that the dissolution and diffusion rate of baicalin from the plant cells were faster heated by microwave radiation. It is known that the microwave heating has the advantages of homogeneous heating, high speed, and high heat efficiency, which may be responsible for the higher extraction efficiency and shorter extraction time [28, 29]. 


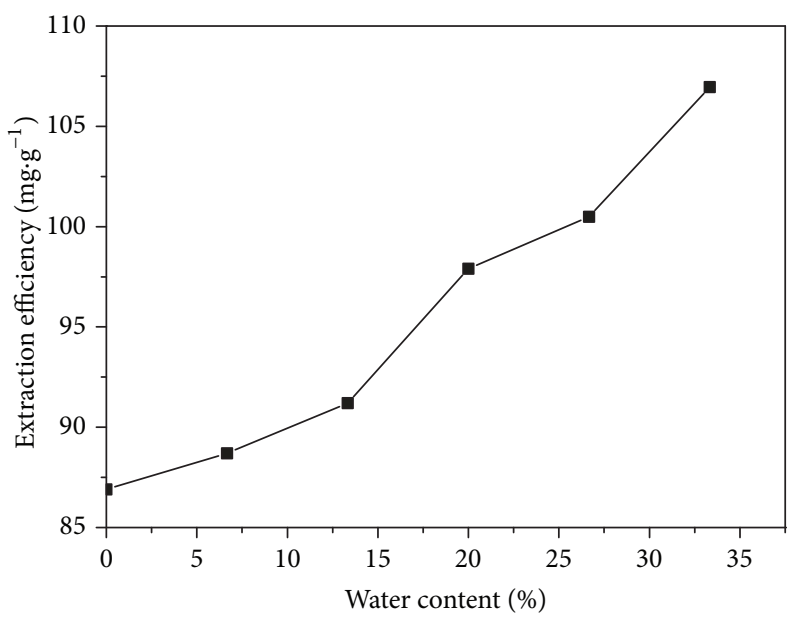

FIGURE 3: Effect of water content in DESs on the extraction ability.

In addition, the DESs can accelerate plant cell rupture and release of the intracellular products by damaging the cell walls [30-33]. Therefore, the DES-based MAE could be developed into a more rapid and effective extraction method for the efficient extraction of target compounds.

\subsection{Microstructure Alterations during the Different Extraction} Procedures. In order to determine microstructure alterations using the different extraction methods, raw and extracted Scutellaria baicalensis Georgi samples were examined by SEM (Figure 4). It can be seen in Figure 4(a) that the external surface of the raw sample was smooth with no apparent disruption on the cell surface. During hot reflux extraction, only a few slightly ruptured (Figures 4(b) and 4(e)); this is due to the fact that the heat transfer was mainly implemented by conduction and convection, which have little effect on the disruption of plant cells. Thus, the target compounds were extracted mainly through solubilization and permeation and the extraction time was long. Following UAE, the sample was partially destroyed and a few significant ruptures were observed on the cell surface (Figures 4(c) and 4(f)); this may be because the ultrasonic energy only has a destructive impact on the plant cell wall. Therefore, only part of target compounds can be extracted and the extraction yields was lower. After extraction using MAE for $10 \mathrm{~min}$, plant cells were not clear and appeared completely disrupted and collapsed in different solvents (Figures 4(d) and 4(g)). In the process of MAE, pressure build-up within the glands could have exceeded their capacity for expansion and caused their rupture more rapidly and completely. Hence, the extraction time was shorter and the extraction yields were higher.

As for the same extraction methods, the degree of disruption of plant cells was in the following order: DESs-based HRAE (Figure 4(b)) > 70 vol\% ethanol-based HRAE (Figure 4(e)), DESs (Figure 4(c))-based UAE > 70 vol\% ethanolbased UAE (Figure 4(f)), DESs-based MAE (Figure 4(d)) $>70$ vol\% ethanol-based MAE (Figure $4(\mathrm{~g})$ ). The results indicated that the plant cells were easily disrupted in DESs conditions.
This may be due to the fact that DESs damage the cell wall by fiber dissolution [34] and the target compounds were extracted from the plant cells.

Generally, the SEM results of microstructure alterations coincided with data on the corresponding extraction efficiency, which demonstrated that cell rupture had a significant effect on extraction [29]. Furthermore, the SEM results revealed the extraction mechanisms from the microstructure point of view.

\section{Conclusions}

The eco-friendliness and low cost of DESs highlight their potential as green solvents for the highly efficient extraction of baicalin from Scutellaria baicalensis Georgi. The most appropriate DES was DES-1, which was screened from the nine hydrophobic DESs by evaluating the equilibrium solubility and extraction efficiency. The extraction conditions were carefully optimized and determined by RSM combined with $\mathrm{BBD}$. Under optimal conditions (extraction temperature of $85^{\circ} \mathrm{C}$, extraction time of $10 \mathrm{~min}$, and a liquid-solid ratio of $\left.23 \mathrm{~mL} \cdot \mathrm{g}^{-1}\right)$, the extraction yield was $106.96 \mathrm{mg} \cdot \mathrm{g}^{-1}$ in DES-1 containing aqueous solutions. When compared with the traditional procedures (e.g., HRAE, UAE), the DESbased microwave-assisted extraction method was demonstrated to have higher feasibility and superiority, and the microstructure alterations following the different extraction procedures confirmed that cell disruption also affected the extraction efficiency. In conclusion, this new method was characterized by mild processing conditions, high-efficiency, eco-friendliness, and easy realization of commercial production. The microstructure alterations following the different extraction procedures confirmed that cell disruption also affected the extraction efficiency.

\section{Conflicts of Interest}

The authors declare that they have no conflicts of interest. 


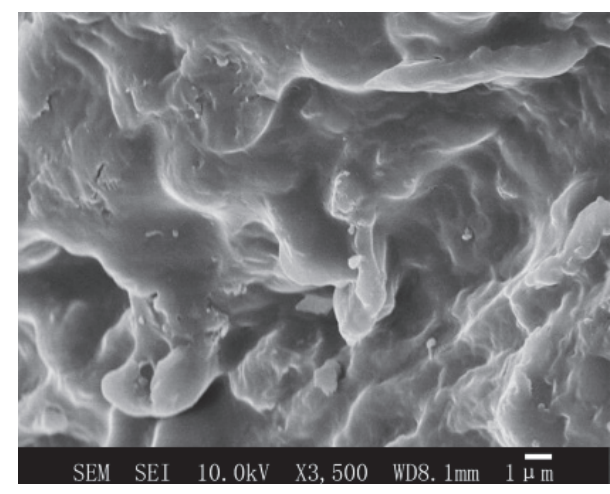

(a)

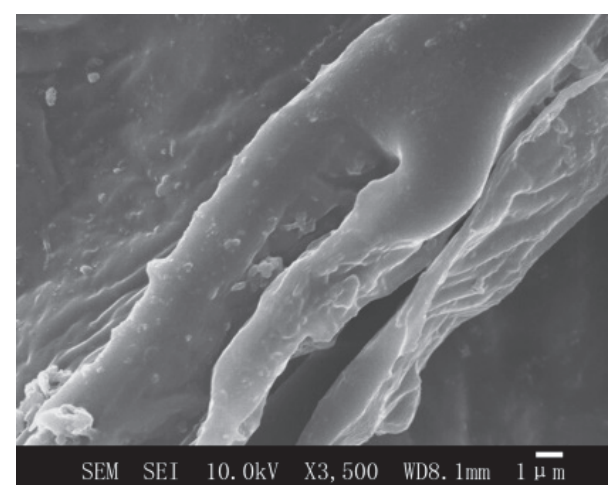

(c)

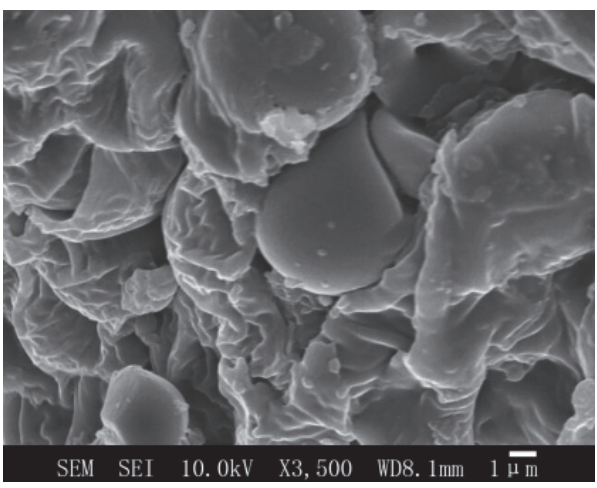

(e)

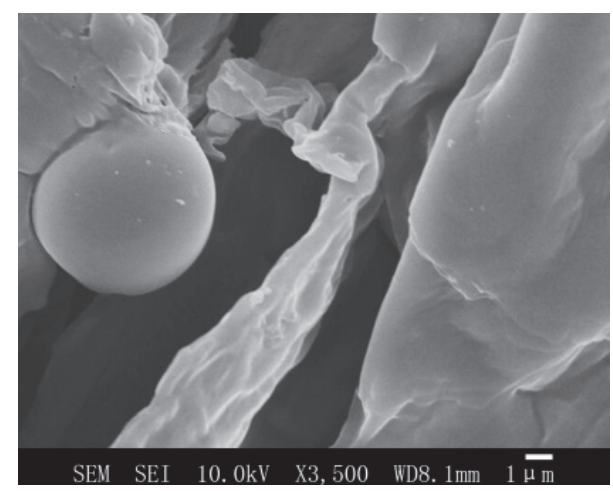

(b)

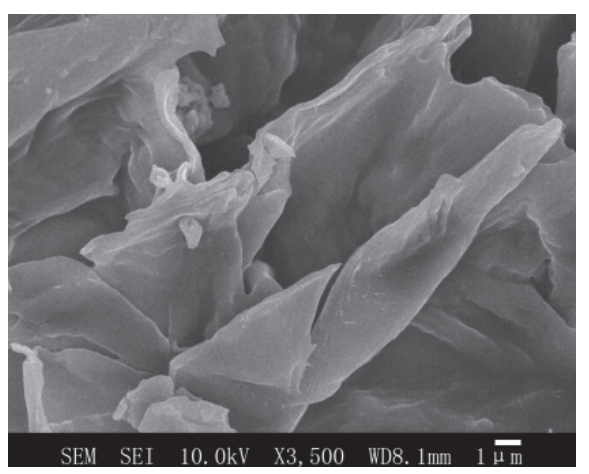

(d)

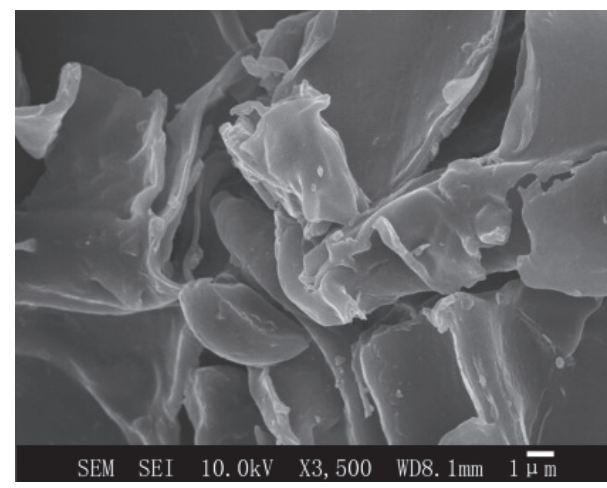

(f)

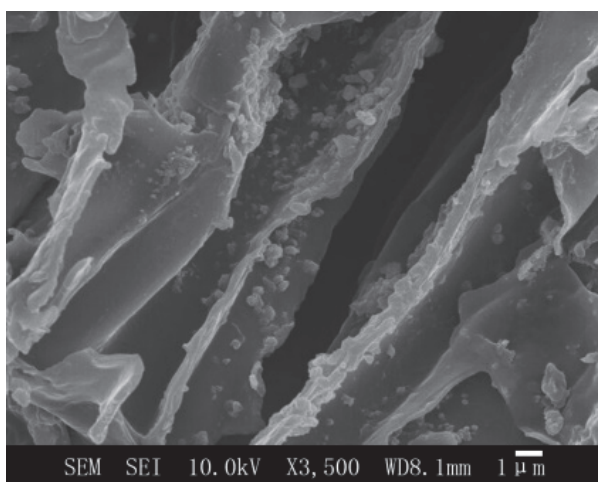

(g)

FIGURE 4: SEM images of Scutellaria baicalensis Georgi samples. (a) Raw materials. (b) DES-based HRAE. (c) DES-based UAE. (d) DES-based MAE. (e) 70\% ethanol-based HRAE. (f) 70\% ethanol-based UAE. (g) 70\% ethanol-based MAE. 


\section{Acknowledgments}

This work was supported by the Science and Technology Innovation Project of Colleges and Universities in Shanxi under Grant no. 2017161 and Natural Science Foundation for Young Scientists of Shanxi Province, China, under Grant no. 2015021034. Research project is supported by Shanxi scholarship council of china (no. 2015-021).

\section{References}

[1] H.-B. Li, Y. Jiang, and F. Chen, "Separation methods used for Scutellaria baicalensis active components," Journal of Chromatography B, vol. 812, no. 1-2, pp. 277-290, 2004.

[2] H. Shi, B. Zhao, and W. Xin, "Scavenging effects of baicalin on free radicals and its protection on erythrocyte membrane from free radical injury," International Journal of Biochemistry and Molecular Biology, vol. 35, no. 5, pp. 981-994, 1995.

[3] E. B. Liu, H. Q. Wei, X. L. Zhao, X. X. Li, and F. X. Jiang, "Determination of baicalin in traditional chinese preparation by high performance liquid chromatography with chemiluminescence detection," Chinese Chemical Letters, vol. 15, no. 9, pp. 10671070, 2004.

[4] Q. Guo, L. Zhao, Q. You et al., "Anti-hepatitis B virus activity of wogonin in vitro and in vivo," Antiviral Research, vol. 74, no. 1, pp. 16-24, 2007.

[5] E. Kowalczyk, P. Krzesiński, M. Kura, J. Niedworok, J. Kowalski, and J. Błaszczyk, "Pharmacological effects of flavonoids from Scutellaria baicalensis," Przeglad Lekarski, vol. 63, no. 2, pp. 9596, 2006.

[6] C. Li, G. Lin, and Z. Zuo, "Pharmacological effects and pharmacokinetics properties of Radix Scutellariae and its bioactive flavones," Biopharmaceutics \& Drug Disposition, vol. 32, no. 8, pp. 427-445, 2011.

[7] J.-F. Liao, W.-Y. Hung, and C.-F. Chen, "Anxiolytic-like effects of baicalein and baicalin in the vogel conflict test in mice," European Journal of Pharmacology, vol. 464, no. 2-3, pp. 141146, 2003.

[8] C.-G. Cheng, W.-Y. Jin, and L.-J. Wu, "Study on microwaveassisted extraction of baicalin from Scutellaria baicalensis," Chemistry and Industry of Forest Products, vol. 25, no. 1, pp. 8183, 2005.

[9] M. A. Rostagno, M. Palma, and C. G. Barroso, "Ultrasoundassisted extraction of isoflavones from soy beverages blended with fruit juices," Analytica Chimica Acta, vol. 597, no. 2, pp. 265-272, 2007.

[10] J.-Y. Hao, W. Han, S.-D. Huang, B.-Y. Xue, and X. Deng, "Microwave-assisted extraction of artemisinin from Artemisia annua L," Separation and Purification Technology, vol. 28, no. 3, pp. 191-196, 2002.

[11] H.-Y. Zhou and C.-Z. Liu, "Microwave-assisted extraction of solanesol from tobacco leaves," Journal of Chromatography A, vol. 1129, no. 1, pp. 135-139, 2006.

[12] Q. Zhang, K. De Oliveira Vigier, S. Royer, and F. Jérôme, "Deep eutectic solvents: syntheses, properties and applications," Chemical Society Reviews, vol. 41, no. 21, pp. 7108-7146, 2012.

[13] A. P. Abbott, G. Capper, D. L. Davies, R. K. Rasheed, and V. Tambyrajah, "Novel solvent properties of choline chloride/urea mixtures," Chemical Communications, vol. 9, no. 1, pp. 70-71, 2003.
[14] M. Hayyan, M. A. Hashim, M. A. Al-Saadi, A. Hayyan, I. M. AlNashef, and M. E. S. Mirghani, "Assessment of cytotoxicity and toxicity for phosphonium-based deep eutectic solvents," Chemosphere, vol. 93, no. 2, pp. 455-459, 2013.

[15] G. Li, D. Deng, Y. Chen, H. Shan, and N. Ai, "Solubilities and thermodynamic properties of $\mathrm{CO}_{2}$ in choline-chloride based deep eutectic solvents," The Journal of Chemical Thermodynamics, vol. 75, pp. 58-62, 2014.

[16] K. Radošević, M. Cvjetko Bubalo, V. Gaurina Srček, D. Grgas, T. Landeka Dragičević, and R. I. Redovniković, "Evaluation of toxicity and biodegradability of choline chloride based deep eutectic solvents," Ecotoxicology and Environmental Safety, vol. 112, pp. 46-53, 2015.

[17] E. L. Smith, A. P. Abbott, and K. S. Ryder, "Deep eutectic solvents (DESs) and their applications," Chemical Reviews, vol. 114, no. 21, pp. 11060-11082, 2014.

[18] M. Francisco, A. Van Den Bruinhorst, and M. C. Kroon, "Lowtransition-temperature mixtures (LTTMs): a new generation of designer solvents," Angewandte Chemie International Edition, vol. 52, no. 11, pp. 3074-3085, 2013.

[19] X.-L. Qi, X. Peng, Y.-Y. Huang et al., "Green and efficient extraction of bioactive flavonoids from Equisetum palustre L. by deep eutectic solvents-based negative pressure cavitation method combined with macroporous resin enrichment," Industrial Crops and Products, vol. 70, pp. 142-148, 2015.

[20] K. M. Jeong, M. S. Lee, M. W. Nam et al., "Tailoring and recycling of deep eutectic solvents as sustainable and efficient extraction media," Journal of Chromatography A, vol. 1424, pp. $10-17,2015$

[21] E. Mouratoglou, V. Malliou, and D. P. Makris, "Novel glycerolbased natural eutectic mixtures and their efficiency in the ultrasound-assisted extraction of antioxidant polyphenols from agri-food waste biomass," Waste and Biomass Valorization, vol. 7, no. 6, pp. 1377-1387, 2016.

[22] T. T. Li, Eutectic Microwave-Assisted solvent Extraction the Main Flavonoids in Scutellaria Baicalensis Georgi, Northeast Forestry University, China, 2014.

[23] Y. Dai, J. Van Spronsen, G.-J. Witkamp, R. Verpoorte, and Y. H. Choi, "Natural deep eutectic solvents as new potential media for green technology," Analytica Chimica Acta, vol. 766, pp. 61-68, 2013.

[24] R. Yusof, E. Abdulmalek, K. Sirat, and M. B. A. Rahman, "Tetrabutylammonium bromide (TBABr)-based deep eutectic solvents (DESs) and their physical properties," Molecules, vol. 19, no. 6, pp. 8011-8026, 2014.

[25] D. J. G. P. Van Osch, L. F. Zubeir, A. Van Den Bruinhorst, M. A. A. Rocha, and M. C. Kroon, "Hydrophobic deep eutectic solvents as water-immiscible extractants," Green Chemistry, vol. 17, no. 9, pp. 4518-4521, 2015.

[26] J. Cao, M. Yang, F. Cao, J. Wang, and E. Su, "Well-designed hydrophobic deep eutectic solvents as green and efficient media for the extraction of artemisinin from artemisia annua leaves," ACS Sustainable Chemistry \& Engineering, vol. 5, no. 4, pp. 3270-3278, 2017.

[27] Q. Cui, X. Peng, X.-H. Yao et al., "Deep eutectic solventbased microwave-assisted extraction of genistin, genistein and apigenin from pigeon pea roots," Separation and Purification Technology, vol. 150, Article ID 12398, pp. 63-72, 2015.

[28] H. Xie, S. Li, and S. Zhang, "Ionic liquids as novel solvents for the dissolution and blending of wool keratin fibers," Green Chemistry, vol. 7, no. 8, pp. 606-608, 2005. 
[29] R. P. Swatloski, S. K. Spear, J. D. Holbrey, and R. D. Rogers, "Dissolution of cellose with ionic liquids," Journal of the American Chemical Society, vol. 124, no. 18, pp. 4974-4975, 2002.

[30] J. Xing, X. Chen, and D. Zhong, "Stability of baicalin in biological fluids in vitro," Journal of Pharmaceutical and Biomedical Analysis, vol. 39, no. 3-4, pp. 593-600, 2005.

[31] Y. Lu, W. Ma, R. Hu, X. Dai, and Y. Pan, "Ionic liquid-based microwave-assisted extraction of phenolic alkaloids from the medicinal plant Nelumbo nucifera Gaertn," Journal of Chromatography A, vol. 1208, no. 1-2, pp. 42-46, 2008.

[32] Y. H. Yao and L. W. Zhang, "Study on stability of Baicalein," Chinese Journal of Spectroscopy Laboratory, vol. 23, pp. 346-348, 2006.

[33] Y. u. BT, Z. R. Zhang, and W. S. Liu, "Studies on stability of Baicalin," Chinese Traditional \& Herbal Drugs, vol. 23, pp. 218220, 2002.

[34] A. A. N. Gunny, D. Arbain, E. M. Nashef, and P. Jamal, "Applicability evaluation of Deep Eutectic Solvents-Cellulase system for lignocellulose hydrolysis," Bioresource Technology, vol. 181, pp. 297-302, 2015. 

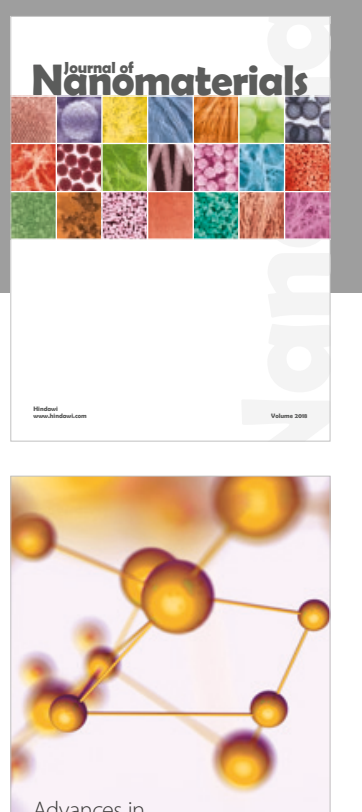

Physical Chemistry
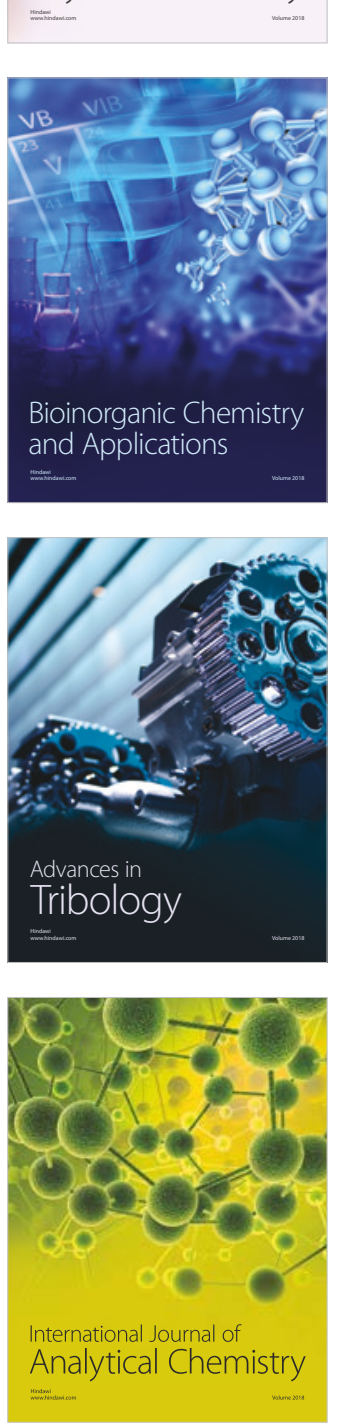

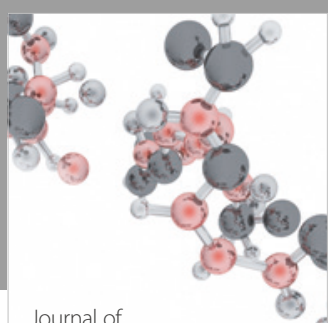

Analytical Methods

in Chemistry

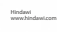

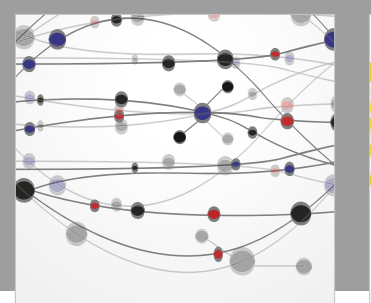

The Scientific World Journal

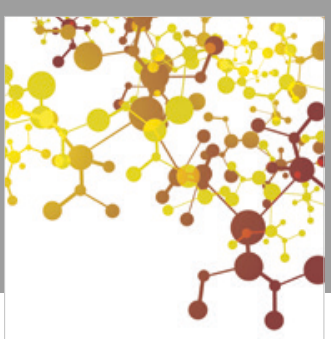

Journal of

Applied Chemistry
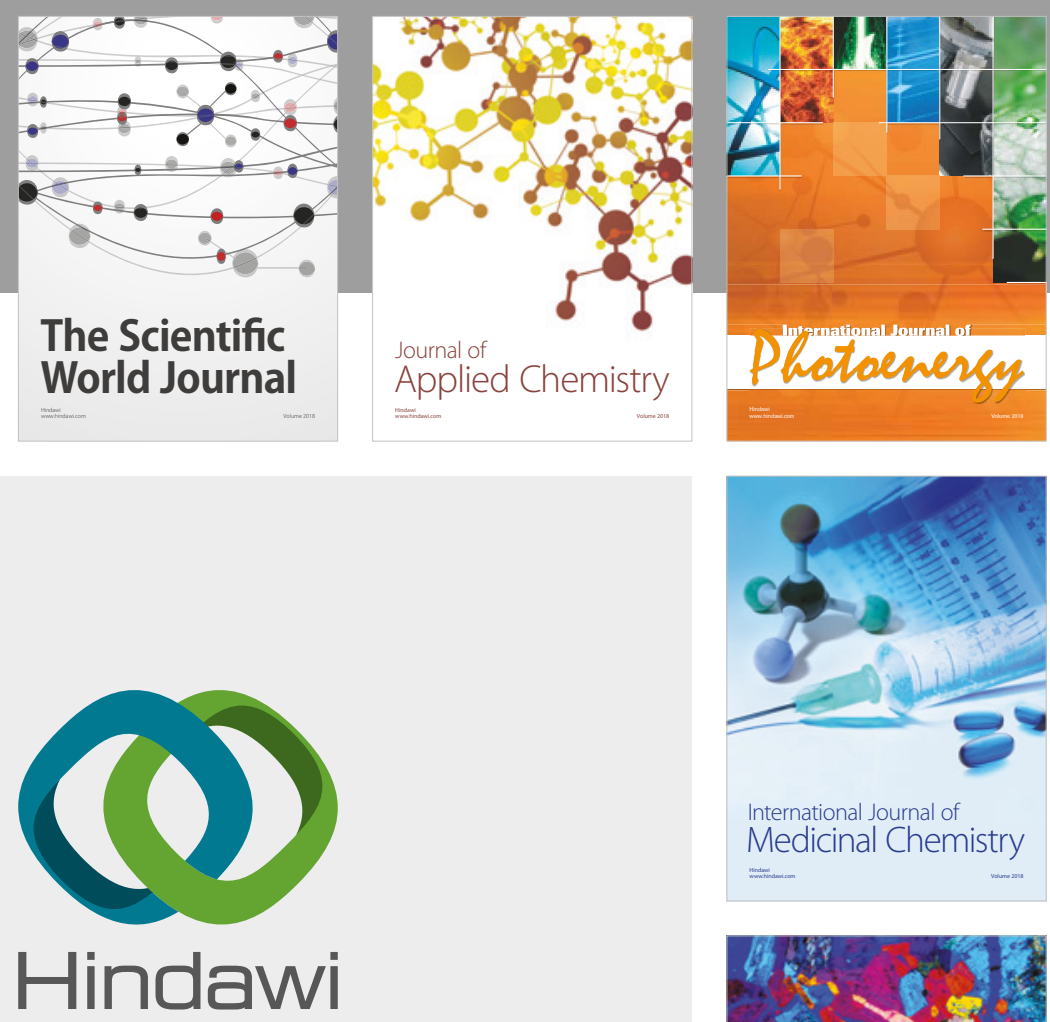

Submit your manuscripts at

www.hindawi.com
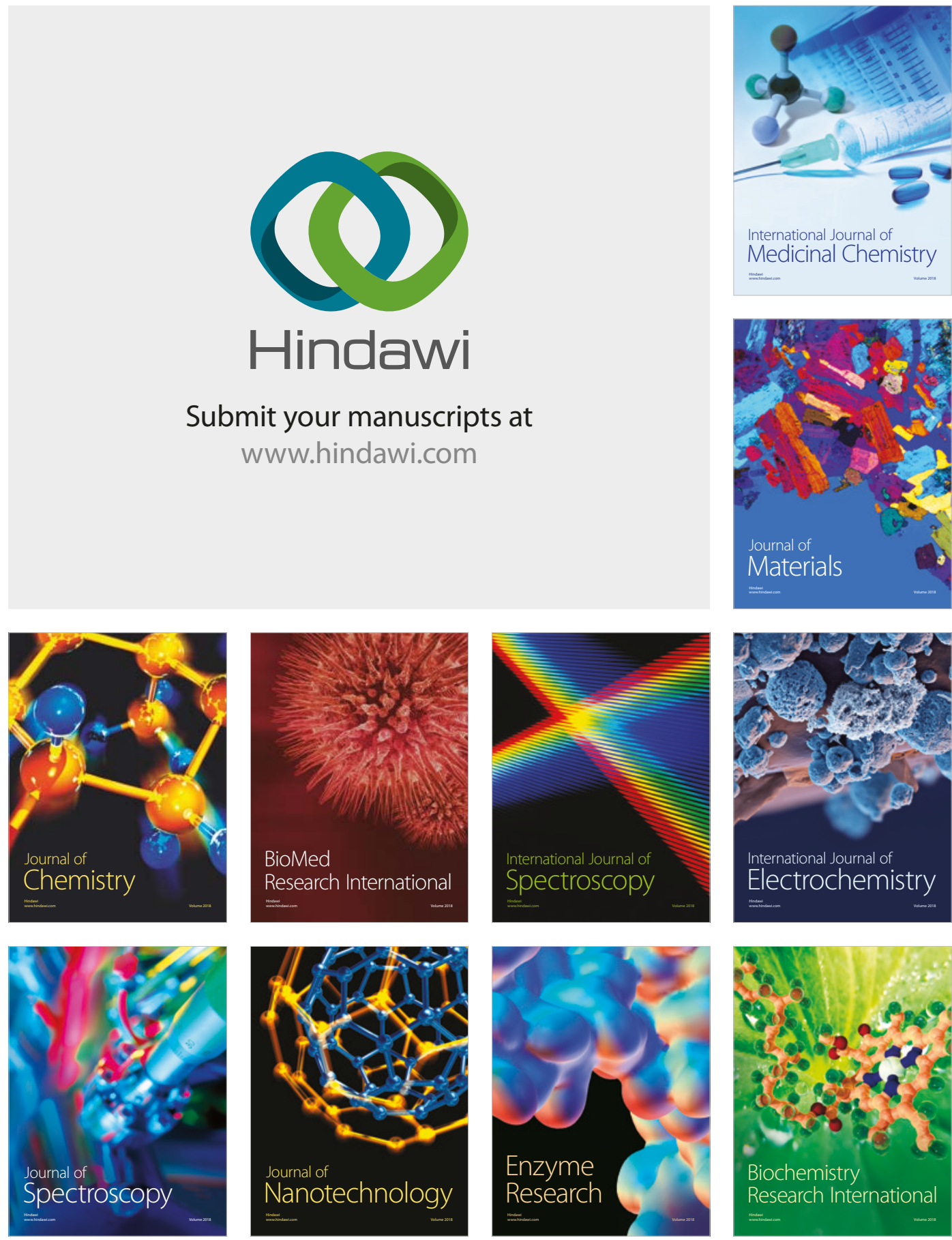
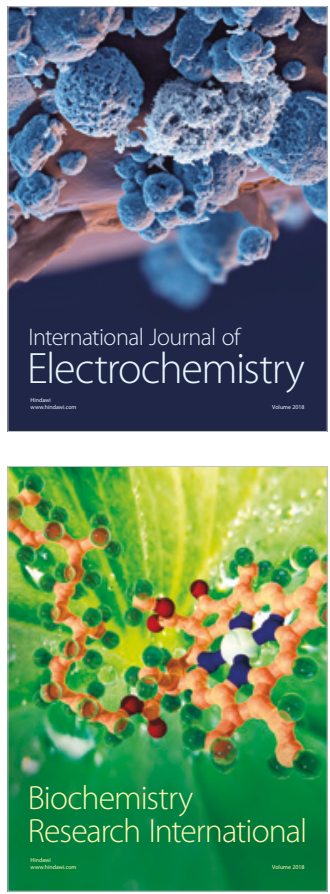